\title{
Chemoselectivity Investigation in Arylations with Diaryliodonium Salts
}

\author{
Joel Malmgren, Nazli Jalalian, Berit Olofsson*
}

Department of Organic Chemistry, Arrhenius Laboratory, Stockholm University, 10691 Stockholm, Sweden

*e-mail corresponding author: berit@organ.su.se

Keywords: Hypervalent iodine compounds, ortho effect, metal-free

\section{INTRODUCTION}

Arylations are important transformations in organic synthesis. Aryl ethers, aryl esters and a-aryl carbonyl compounds are important substructures in a variety of compounds such as pharmaceuticals and natural products. ${ }^{1}$

Diaryliodonium salts have recently been recognized as versatile reagents in organic synthesis. ${ }^{2}$ They can be employed both in metal-mediated and metal-free reactions, thereby avoiding the drawbacks of organometallic reagents i.e. toxicity and high cost. ${ }^{3}$ Efficient one-pot procedures to diaryliodonium salts have been developed within our group (Scheme 1) increasing the availability of these compounds. ${ }^{4}$

Scheme 1. One-pot routes to diaryliodonium salts

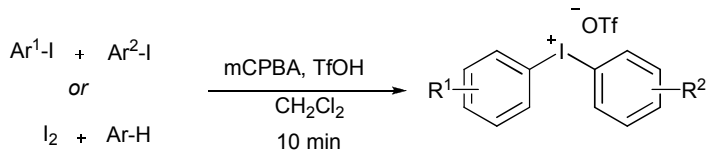

With fast and inexpensive procedures for the preparation of these salts in hand, we are currently investigating the electrophilic arylating potential of these reagents. ${ }^{5}$

\section{RESULTS AND DISCUSSION}

Unsymmetric diaryliodonium salts $\left(R^{1} \neq R^{2}\right)$ are sometimes preferred due to economic and accessibility reasons. Thus it is important to understand and predict which aryl moiety is transferred to the nucleophile, i.e. the chemoselectivity of the process. In metal-mediated reactions, the aryl group with the least steric bulk is transferred. $^{2}$ In metal-free reactions, an orthosubstituted aryl group is sometimes transferred preferentially over a less hindered aryl moiety although electronic factors are also important. ${ }^{5 \mathrm{c}}$ These steric and electronic effects often oppose one another, which make the chemoselectivity difficult to predict. Therefore, a detailed investigation into the chemoselectivity is currently being performed. A series of unsymmetric diaryliodonium salts was reacted with phenols, carboxylic acids and malonates (Figure 1) under metal-free conditions. The observed trends will be discussed.
Figure 1. Nucleophiles and diaryliodonium triflates used in the study

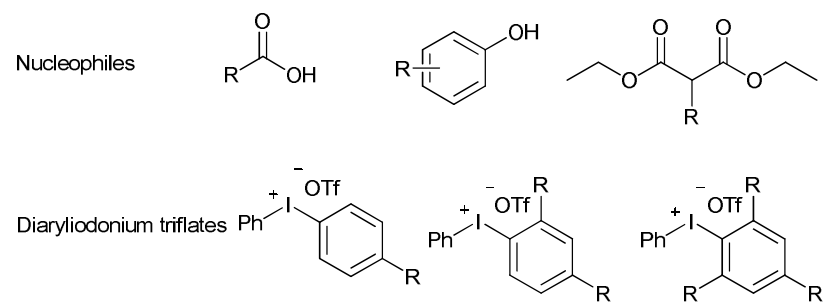

The difference in chemoselectivity can be demonstrated using the effects of having steric bulk in ortho-position employing a phenol and diethylmethyl malonate respectively as nucleophile acting on (phenyl)("arene")lodonium triflate, where the arene is $p$-tolyl or mesitylene. The mixtures obtained from the phenol were isolated in yields up to $84 \%$ in a $2.9: 1$ and $1: 1.9$ ratio respectively where the first number in each ratio is the phenyl group. Diethylmethyl malonate gave a different selectivity. The (phenyl) ( $p$-tolyl)lodonium triflate gave the same $3: 1$ ratio towards transfer of the phenyl and the (phenyl)(mesityl)lodonium triflate gave a 99.8:0.2 ratio, also towards transfer of the phenyl, both isolated in $56 \%$ yield. Steric bulk in ortho-position can either hinder or facilitate transfer of that arene.

\section{ACKNOWLEDGEMENTS}

This work was financially supported by the Swedish Research Council, STINT and the $\mathrm{K}$ \& A Wallenberg Foundation.

\section{REFERENCES}

1. (a) Frlan, R.; Kikelj, D., Synthesis 2006, 2271; (b) LloydJones, G. C., Angew. Chem. Int. Ed. 2002, 41, 953.

2. Phipps, R. J.; Gaunt, M. J., Science 2009, 323, 1593.

3. Merritt, E. A.; Olofsson, B., Angew. Chem. Int. Ed. 2009, 48, 9052.

4. (a) Bielawski, M.; Aili, D.; Olofsson, B., J. Org. Chem. 2008, 73, 4602; (b) Bielawski, M.; Zhu, M.; Olofsson, B., Adv. Synth. Cat. 2007, 349, 2610; (c) Merritt, E. A.; Malmgren, J.; Klinke, F. J.; Olofsson, B., Synlett 2009, 2277; (d) Zhu, M. Z.; Jalalian, N.; Olofsson, B., Synlett 2008, 592.

5. (a) Jalalian, N.; Ishikawa, E. E.; Silva, L. F.; Olofsson, B., Org. Lett. 2011, 13, 1552;

(b) Norrby, P. O.; Petersen, T. B.; Bielawski, M.; Olofsson, B., Chem. Eur. J. 2010, 16, 8251; (c) Petersen, T. B. Khan, R.; Olofsson, B. submitted. 